\title{
Seasonal comparison of active v/s passive electrical characteristics of skeletal muscle fiber membranes of the reptile, Uromastix hardwickii
}

\begin{abstract}
Introduction: This comparative study deals with the observation of changes with temperature variations of the seasons in the muscular active versus passive electrical excitability characteristics in the reptile Uromastix hardwickii.

Objectives: The present study was carried out to investigate seasonal comparison of active electrical characteristics (resting membrane potential, maximum depolarization potential, duration of depolarization and repolarization potentials) and passive electrical characteristics (threshold potential, after-potential $\{\mathrm{AHP}\} \&$ its duration), which are not studied earlier.

Methods: Freshly captured adult animals of both the sexes were used in all the experiments, and the gastrocnemius (skeletal) muscles were dissected out. The muscle samples were digested with digestive fluid (pepsin $\& \mathrm{HCl}$ ), stirred, settled and supernatant was removed, till whitish fluid having clear cells obtained for patch clamp recording of ionic currents and potentials (active and passive electrical potentials). Resting membrane potentials and action potentials of reptilian skeletal muscle cell membranes were measured in whole cell current mode. The glass microelectrodes, with a tip diameter 2-3 $\mu \mathrm{m}$ and tip resistance 5-6 M $\Omega$ (when filled with intracellular solution) were used in these experiments.

Results: The average mean values of the active electrical characteristics were stable and showed no any significant change $(\mathrm{P}>0.05)$ with season, but the passive electrical characteristics were found to fall significantly $(\mathrm{P}<0.05)$ from winter towards summer $\&$ vice versa; therefore the passive electrical characteristics/parameters affect muscular excitability and probably muscular activities of the animal from winter towards summer.

Conclusion: Seasonal temperature changes in passive electrical characteristics of the skeletal muscles of the Uromastix hardwickii are responsible for the change in the active behavior \& homeostasis of these reptiles from summer towards winter by raising their muscular electrical excitability to cause some required movements during winter sleep/ hibernation.
\end{abstract}

Keywords: patch-clamp technique, Uromastix hardwickii, gastronomies muscle, seasonal temperature, active and passive electrical parameters
Volume 2 Issue 2 - 2016

\author{
Mohammad Saleh Soomro,' Zafar Latif \\ Awan, ${ }^{2}$ Mohammad Ashfaq Ali, ${ }^{3}$ Mohammad \\ Waseem Soomro \\ 'Department of Physiology, Baqai Medical University, Pakistan \\ ${ }^{2}$ Department of Community Medicine, Rai Medical College, \\ Pakistan \\ ${ }^{3}$ Department of Biochemistry, Liaquat National Medical College, \\ Pakistan \\ ${ }^{4}$ Mechanical Department of NED Engineering University, \\ Pakistan
}

Correspondence: Mohammad Saleh Soomro, Department of Physiology, Baqai Medical University, Karachi, Pakistan, Tel 009234410438, 00923012591215,

Email msaleh.soomro5।@gmail.com

Received: December 08, 2015 | Published: January 27, 2016
Abbreviations: RMP, resting membrane potentials; GRB, general reptilian buffer; THP, threshold potential; AHP, after-hyper polarization potential; ANOVA, analysis of variance

\section{Introduction}

The reptile, Uromastix hardwickii, looks like a long spiny-tailed lizard, is found in the desert areas of Asian \& African countries; and is herbivorous. Local people hunt it to have its fat. Which is boiled down and the resulting oil is used to relieve pain, and also as a cure for impotency. ${ }^{1-3}$ The skeletal muscle membranes of these reptiles are found to exhibit membrane potentials, as being permeable to $\mathrm{Na}+$, $\mathrm{K}+$ and $\mathrm{Cl}-.^{4-7}$ These muscle cell membrane electrical potentials/ characteristics have been divided into active and passive categories; the passive electrical characteristics show some thermal dependency in different species of the animals. ${ }^{8,9}$ As the, passive electrical properties are important in determining the excitability of muscle fibers. ${ }^{8}$

Electro physiologists, now-a-days use patch-clamp technique, that is a refinement of voltage clamp; for studying single and multiple ion channels in cells to record the membrane potentials/currents of the cells, especially in excitable nerve \& muscle cells. ${ }^{10-13}$ Very little is known about the active and passive electrical characteristics of this reptile/lizard Uromastix hardwickii, except a few works on some other lizard species skeletal muscles by Adams $\mathrm{BA}^{8}$ observed temperature effects on membrane chloride conductance and recorded decreased electrical excitability of lizard skeletal muscle fibers with increasing temperature to $45^{\circ} \mathrm{C}$. He recorded resting membrane potentials (RMP) of $-80 \mathrm{mV}$ and $-70 \mathrm{mV}$ of the skeletal muscle fibers of those lizards. Seasonal temperature effects potentials in other species of animals are also studied by various workers. ${ }^{14-16}$

\section{Materials and methods}

The study was carried out in peak winter months of December \& January, the temperature ranged between 20 to $24^{\circ} \mathrm{C}$ and summer months of June \& July between the temperature range of 32 to $36^{\circ} \mathrm{C}$, at University of Karachi, Pakistan. Fresh animals (adults) of both the sexes were used in all the experiments. In the laboratory, the animals were kept at room temperature $\left(25^{\circ} \mathrm{C}\right)$. Since their biochemistry is 
reported to change with season, ${ }^{17}$ all the animals of a fresh batch were used up within a week, and for experimental purpose, the animals were killed by decapitation and the gastrocnemius (skeletal) muscles of both the limbs were dissected out. ${ }^{2} 1 \mathrm{gm}$ muscle sample was digested in $10 \mathrm{ml}$ digestive fluid, containing $1 \%(\mathrm{w} / \mathrm{v})$ pepsin $(0.1 \mathrm{gm})$ and $1 \%(\mathrm{v} / \mathrm{v}) \mathrm{HCl}(0.1 \mathrm{ml})$ and $9.9 \mathrm{ml}$ water. Magnetic stirring of the mixture was carried out for 3 hours at $37^{\circ} \mathrm{C}$, the digest was settled for 20 minutes and $2 / 3$ rd supernatant removed. The deposit was filtered through $355 \mu \mathrm{m}$ mesh, settled again for 20 minutes and then supernatant fluid removed. Afterwards the sediment was washed with warm $\left(37^{\circ} \mathrm{C}\right)$ water, settled and supernatant removed till the whitish fluid volume of $1 \mathrm{ml}$ was left, having the clear muscle cells for electrical recording. ${ }^{18-20}$ The membrane potentials were measured by the patch-clamp method as described by Hamill OP et al. ${ }^{10}$ the glass microelectrodes used in patch-clamp technique had tip diameter 2-3 $\mu \mathrm{m},{ }^{9,20}$ tip resistance 5-6 M $\Omega .{ }^{11}$ The microelectrodes were filled with intracellular solution (in mM $145 \mathrm{KCl}, 10 \mathrm{NaCl}, 10$ EGTA, 1 $\mathrm{MgCl}, 2 \mathrm{CaCl} 2$ and 10 Hepes buffer; by using $1 \mathrm{ml}$ syringe. ${ }^{11,21}$ The muscle cells mounted in microscope were perfused with general reptilian buffer (GRB), as described by Khalil $\mathrm{F}^{22}$ The intracellular solution, used in patch-pipette had lower osmolality $(266 \mathrm{mOsm} / \mathrm{L})$ than that of extracellular solution (GRB) $(307 \mathrm{mOsm} / \mathrm{L})$; in order to improve seal formation ${ }^{10}$ and prevent cell swelling which may occur during long time recordings. ${ }^{21}$ The parameters measured by patchclamp technique, were active electrical characteristics/parameters: resting membrane potential (RMP), action potential (maximum depolarization potential \& its duration, repolarization potential), and passive electrical parameters: threshold potential (THP), after-hyper polarization potential (AHP)/+ve after-potential \& their durations. All of the calculations including multiplications, divisions, averages, standard errors and ' $t$ ' tests and P-values done in the present work were carried out on MS Office Excel and Minitab version 13.30. The one way analysis of variance (ANOVA) was evaluated. P-Value approach was adopted which suggested the evidence in favor of or against the null hypothesis; keeping in consideration the degree of freedom for variation associated "between the treatments" (peak winter \& summer) and "within the treatment". Hypothesis was rejected for P-value smaller than $0.05{ }^{23}$

\section{Results}

By comparing the electrical parameters (active \& passive) obtained during peak winter (Figure 1) and summer (Figure 2) months, it was observed that:

i. Resting Membrane Potential (RMP) (mV): Average mean values mentioned in Table 1, showed insignificant difference, from winter to summer.

ii. Action Potential:

a) Maximum depolarization/action Potential (mV) (active electrical parameter): The average values of this phase of action potential (Table 1), showed insignificant difference in between peak winter and summer months.

b) Duration of depolarization (ms) (active electrical parameter): According to the average values of this electrical parameter (Table 1), which was measured from threshold potential toward the peak, were found to have insignificant difference in between peak winter and summer months.

c) Threshold potential $(\mathrm{mV})$ (passive electrical parameter): According to Table 1, the average values of this electrical parameter, were found to have highly significant $(\mathrm{P}<0.01)$ difference in between peak winter and summer months. This difference demonstrated $10 \%$ lesser values of this parameter in summer months.

d) Maximum After-hyper polarization Potential (AHP) (mV) (passive electrical parameter): The average values of this electrical parameter mentioned in Table 1, demonstrated highly significant $(\mathrm{P}<0.01)$ fall from peak winter towards summer months. This fall was calculated to be $9 \%$ from winter in the average values of maximum hyper polarization potential.

e) Duration of repolarization (ms) (active electrical parameter): According to Table 1, the average values of this electrical parameter were found to decrease insignificantly in between peak winter and summer months.

f) Duration of $\mathrm{AHP} /+\mathrm{Ve}$ after-potential (ms) (passive electrical parameter): The average values of this electrical parameter mentioned in Table 1 , highly significant $(\mathrm{P}<0.01)$ fall was noted, this fall was calculated to be $12 \%$ toward summer.

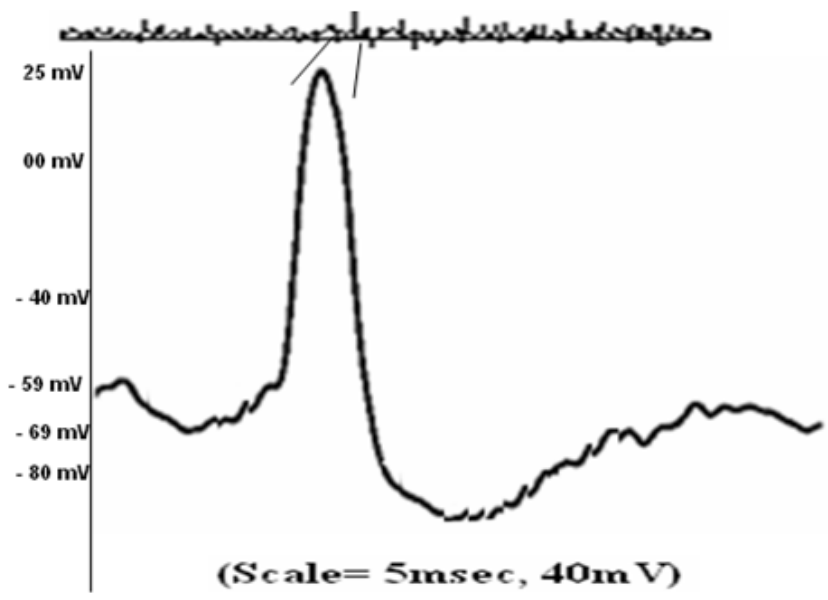

Figure I Patch-clamp winter recording of electrical parameters (resting membrane potential: $-69 \mathrm{mV}$, threshold potential: $-59 \mathrm{mV}$, maximum depolarization potential: $25 \mathrm{mV}$ ) of gastrocnemius muscles of Uromastix hardwickii.

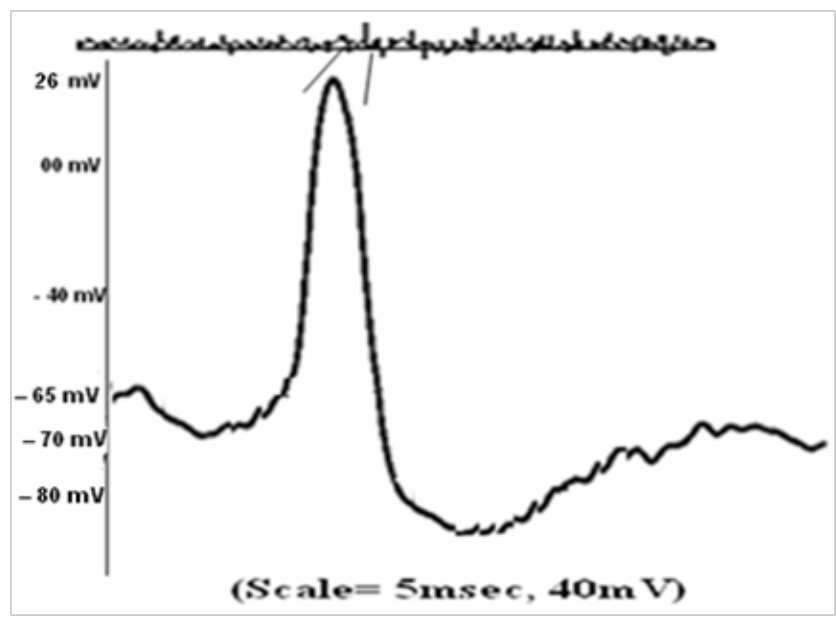

Figure 2 Patch-clamp summer recording of electrical parameters (resting membrane potential: $-70 \mathrm{mV}$, threshold potential: $-65 \mathrm{mV}$, maximum depolarization potential: $26 \mathrm{mV}$ ) of Gastrocnemius muscles of Uromastix hardwickii. 
Table I Seasonal comparison of active v/s passive electrical characteristics (parameters) of skeletal muscle membranes, of Uromastix hardwickii, obtained by patch-clamp technique during winter and summer months

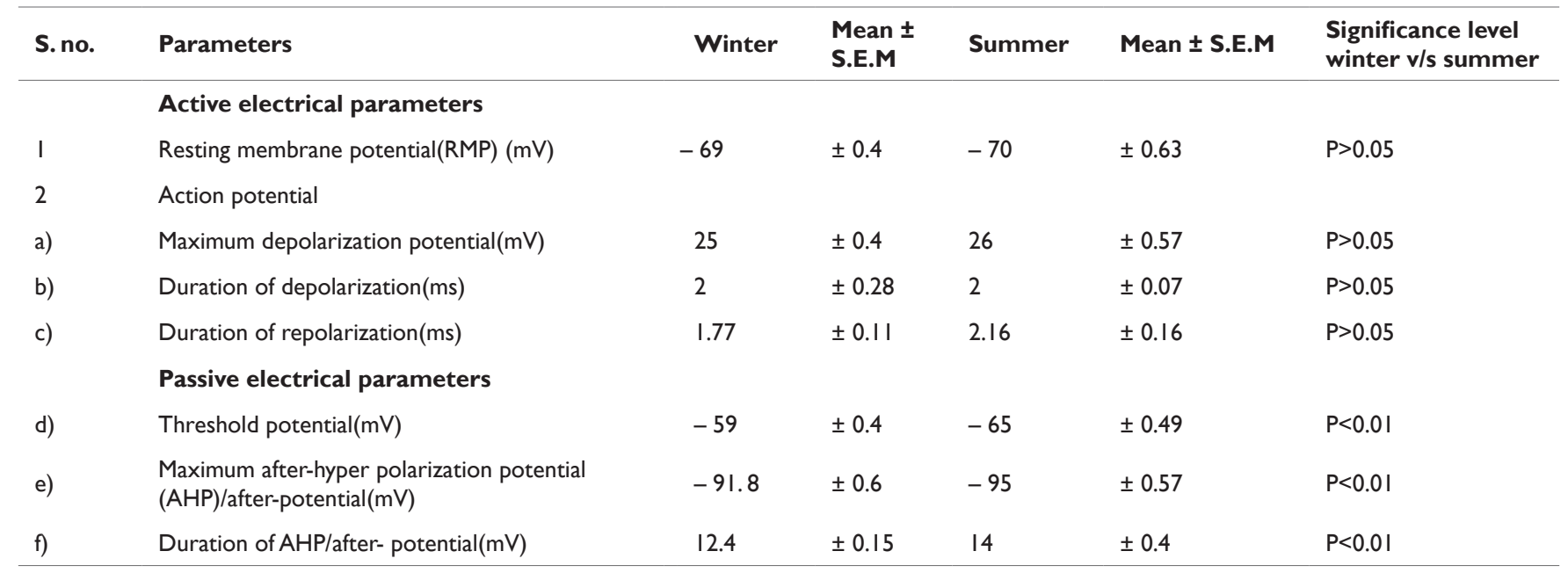

Note RMP recorded as holding potential

$\mathrm{P}<0.05$ denotes the significant values

$\mathrm{P}>0.05$ denotes the insignificant values

\section{Discussion}

It is worth to mention that seasonal changes are invariably associated with changes in environmental temperature, and are analogous to changes in experimental temperature. The information on thermal dependence regarding the electrical properties (active $\&$ passive) of reptilian muscle fiber membrane is rather scanty, except few works by some researchers ${ }^{8}$ demonstrated the effects of experimental temperatures on electrical excitability by chloride conductance of lizard/desert iguanas (Dipsosaurus dorsalis) skeletal muscle, and observed decreased electrical excitability with increasing temperature. ${ }^{9}$ Worked on both the season \& the experimental temperature, and observed changes in the generation of spontaneous action potential discharge that increased with the fall of temperature $\&$ vice versa in sinus venosus (heart muscle) of European flat fish ${ }^{24}$ also observed increased action potential discharge rate of pacemaker cells in cold conditions of fish heart. ${ }^{25}$ Observed increased excitatory junction potential amplitudes in cold acclamation in ectothermal crab ${ }^{26}$ demonstrated effects of season on the conduction velocity of action potential that increased with decreased temperature; in squid giant axon. ${ }^{27}$ Also observed increased firing rate (excitability) in a songbird pre-motor nucleus. While studying the electrical characteristics/ parameters of the skeletal muscle fiber membrane of our experimental animal/lizard Uromastix hardwickii, recorded during the peak winter December \& January and peak summer months of June \& July; it was obvious that active electrical characteristics: resting membrane potential (RMP), action potential (Figure 1) (Figure 2), their durations were stable with the change of season from summer towards winter (Table 1); with insignificant changes. But the passive electrical characteristics: threshold potential (THP), after-potential (after-hyper polarization potential/AHP) and the duration of after-potential were influenced and changed significantly with season (Table 1). That these two potential (THP, AHP) values decreased in negativity/increased positivity and the duration of AHP also remarkably decreased with the fall of temperature in the peak winter months of December \& January, thus showing higher muscular electrical excitability in these colder months as compared to hotter season of June \& July. Therefore it is suggested that gastrocnemius (skeletal) muscles of Uromastix hardwickii undergo excitability changes (because of changes in passive electrical characteristics) between winter and summer; especially increased muscle electrical excitability, due to changes in passive electrical characteristics, during fall of the temperature in winter, which is helpful to cause some sluggish movements during winter sleep/hibernation. Also all of the above mentioned references guiding the increased electrical excitability, during fall of the temperature in winter in other species of the animals; support our findings, of seasonal changes in the passive electrical parameters which are studied and compared with active electrical characteristics (not influenced by seasonal temperature changes) for the first time in the skeletal muscle of Uromastix hardwickii. Our study on skeletal muscle tissues of this animal studied are very much relevant with humans, hence hints to expand further research through the living tissues of Uromastix; which can't be carried out on living human beings. This animal is desert-adapted \& very much resistant to the conditions of food shortages, and lives for several days without any food or water because of its fat storages. ${ }^{21}$

\section{Conclusion}

Seasonal temperature changes in all the above mentioned passive electrical parameters of the skeletal muscles of the Uromastix hardwickii are definitely responsible for the change in the active behavior \& homeostasis of these animals from summer towards winter by raising their muscular electrical excitability to cause some required movements during winter sleep/hibernation.

\section{Acknowledgements}

None.

\section{Conflict of interest}

Author declares that there is no conflict of interest.

\section{References}

1. Dutta S, Jhala Y. Ecological aspects of Indian spiny-tailed lizard Uromastyx hardwickii in Kutch. J Bombay Nat Hist Soc. 2007;104(3):255-265. 
2. Azeem MA, Shaikh HA. Effect of season on length-tension relation of gastrocnemius muscle of Uromastix hardwickii. Pak J Physiol. 2006;2(1):1-4.

3. Daniels JC. The Book of Indian Reptiles and Amphibians. Bombay Natural History Society, Mumbai; 2002.

4. Guyton AC, Hall JE. Membrane physiology, nerve and muscle. In: Text book of Medical Physiology. 12th ed. 2011:45-71.

5. Ganong WF. In Medical review book. 23rd ed. USA: Appletons and Lange Publications; 2010:5-8

6. Soomro MS, Karira KA, Mangi FH, et al. Calculation of Resting membrane potential of a large nerve and skeletal muscle fiber, by the solution of Goldman equation. Specialist - Pakistan's J Med Sc. 1999;15(4):271-275.

7. Gelband CM, Greco PG, Martens JR. Voltage dependent chloride channels, invertebrates to man. J Exp Zool. 1996;275(4):277-282.

8. Adams BA. Temperature effects on membrane chloride conductance and electrical excitability of lizard skeletal muscle. $J$ exp Biol. 1989;144:551-563.

9. Harper AA, Newton IP, Watt PW. The effect of temperature on spontaneous action potential discharge of the isolated sinus venosus from winter and summer plaice (Pleuronectes platessa). J Exp Biol. 1995;198(1):137-140

10. Hamill OP, Marry A, Neher E, et al. Improved patch-clamp techniques for high-resolution current recording from cells/cell membrane patches. Pflugers Archive. 1981;391(2):85-100.

11. Fatima-shad K, Barry HA. patch-clamp study of GABA- and strychninesensitive glycine-activated currents in post-natal tissue-cultured hippocampal neurons. Proc R Soc Lond B. 1992;250(1328):99-105.

12. Moorhouse AJ, Li S, Vichery RM, et al. A patch-clamp investigation of membrane currents in a novel mammalian retinal.ganglion cell line. Brain Res. 2004;1003(1-2):205-208.

13. Soomro MS, Mahar SA, Qureshi AA, et al. Thermal dependency of electrical excitability of gastrocnemius (skeletal) muscle in the desertreptile, Uromastix hardwickii. Journal of Taylor \& Francis-Biological Rhythm Research. 2014;1(1):51-55.

14. Park KH, Meitzen J, Moore IT, et al. Seasonal-like plasticity of spontaneous firing rate in a songbird pre-motor nucleus. $J$ Neurobiol 2005;64(2):181-191.
15. Meitzen J, Perkel DJ, Brenowitz EA. Seasonal changes in intrinsic electrophysiological activity of song control neurons in wild song sparrow. J Comp Physiol A Neuroethol Sens Neural Behav Physiol. 2007;193(6):677-683.

16. Meitzen J, Weaver AL, Brenowitz EA, et al. Plastic and stable electrophysiological properties of adult avian forebrain songcontrol.neurons across changing breeding conditions. $J$ Neurosci. 2009;29(20):6558-6567.

17. Zain AM, Zain BK, Rehman AM. Blood electrolytes of a Lizard. Pak J Biochem. 1969;2(2):47-49.

18. Serrano FJ, Perez-martin JE, Reina D, et al. Influence of infection intensity on predilection sites in swine trichinellosis. $J$ Helminthol. 1999;73(3):251-254.

19. Dubey JP. Refinement of pepsin digestion method for isolation of toxoplasma gondii from infected tissues. Veterinary parasitology. 1998;74(1):75-77.

20. Malakauskas A, Kapel CMO. Tolerance to low temperature of domestic and sylvatic trichinelspp in rat muscle tissue. $J$ Parasitol. 2003;89(4):744-748

21. Hayar A, Gu C, Chaer EDA. An improved method for patch-clamp recording and calcium imaging of neurons in the intact dorsal root ganglion in rats. J Neurosci Methods. 2008;173(1):74-82.

22. Khalil F, Messeih G. Tissue constituents of reptiles in relation to their mode of life: Lipid content. Comp Biochem Physiol. 1962;6(2):171-174.

23. Walpole RE, Myers RH, Myers SL, et al. Probability \& statistics for engineers and scientists. 7th ed. Prentice Hall; 2002. p. 9, 12, 186-204, 284-290, 307-313, 461-471

24. Jaako H. Effects of temperature on the electrical excitability of fish cardiac myocytes. 2008.

25. Suhaila Q. Adaptive responses to temperature and photoperiod in neuromuscular transmission in ectothermal crab Carcinus maenas (l) $\mathrm{E}$ Thesis Darham University; 2004.

26. Joshua JCP, Bezanilla F. Seasonal variation in conduction velocity of action potentials in Squid giant axons. The Biol Bull. 2000;199(2):135-143.

27. Park KH, Meitzen J, Moore IT, et al. Seasonal-like plasticity of spontaneous firing rate in a songbird pre-motor nucleus. J Neurobiol. 2005;64(2):181-191. 